\title{
Effect of Hoechst 33342 on stallion spermatozoa incubated in KMT or Tyrodes modified INRA96
}

\author{
C Balao da Silva, Heriberto Rodriguez-Martinez and C Ortega-Ferrusola
}

\section{Linköping University Post Print}

N.B.: When citing this work, cite the original article.

Original Publication:

C Balao da Silva, Heriberto Rodriguez-Martinez and C Ortega-Ferrusola, Effect of Hoechst 33342 on stallion spermatozoa incubated in KMT or Tyrodes modified INRA96, 2012, Animal Reproduction Science, (131), 3-4, 165-171.

http://dx.doi.org/10.1016/j.anireprosci.2012.01.003

Copyright: Elsevier Masson http://www.elsevier-masson.fr/

Postprint available at: Linköping University Electronic Press

http://urn.kb.se/resolve?urn=urn:nbn:se:liu:diva-79110 
1 Effect of Hoechst 33342 on stallion spermatozoa incubated in KMT or Tyrodes modified 1

\section{INRA96}

Laboratory of Equine Reproduction, Veterinary Teaching Hospital, Department of Medicine, Faculty of Veterinary Medicine, University of Extremadura, Cáceres, Spain, ${ }^{2}$ Department of Clinical Sciences Swedish University of Agricultural Sciences and ${ }^{3}$ Department of Clinical and Experimental Medicine, Linköping University Linköping, Sweden

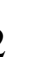

*Correspondence to Dr. FJ Peña Veterinary Teaching Hospital, Laboratory of Equine Reproduction, Faculty of Veterinary Medicine University of Extremadura Avd de la Universidad s/n 10003 Cáceres Spain; E-mail - fjuanpvega@unex.es

\section{ABSTRACT}

The only known means of effectively separating populations of $\mathrm{X}$ and $\mathrm{Y}$ bearing sperms is the Beltsville sexing technology. The technology implies that each individual sperm is interrogated for DNA content, measuring the intensity of the fluorescence after staining the spermatozoa with Hoechst 33342. Because there are no data regarding the effect of the staining on stallion sperm, ejaculates were incubated up to 90 minutes in presence of $0,4.5,9$, 22.5, 31.5, 45, 54, 67.5, 76.5 and $90 \mu \mathrm{M}$ of Hoechst 33342, in two media, KMT or INRA- 
Tyrodes. After 40 and 90 minutes of incubation, motility (CASA) and membrane integrity (flow cytometry after YoPro-1/Eth staining) were evaluated. In KMT extender sperm motility significantly decreased after 45 minutes of incubation when sperm were incubated in the presence of concentrations of Hoechst of $45 \mu \mathrm{M}$ or greater $(P<0.05)$. When incubated in modified INRA96, stallion spermatozoa tolerated greater concentrations of Hoechst, because sperm motility only decreased when incubated in presence of $90 \mu \mathrm{M}(P<0.05)$ and membrane integrity was not affected. After 90 minutes of incubation the same effect was observed, but in this case at concentrations over $45 \mu \mathrm{M}$ the percentage of total motile sperm was also reduced although only in samples incubated in KMT. To produce this effect in samples incubated in Tyrodes modified INRA 96, Hoechst had to be present at concentrations over $67.5 \mu \mathrm{M}$. Apparently, the detrimental effect of Hoechst to stallion spermatozoa varies depending on the media, and INRA modified extender may be an alternative to KMT.

Keywords: Stallion, Sperm, CASA, Hoechst 33342, Sex sorting

\section{Introduction}

The selection of the sex of the foal will offer obvious advantages for the horse industry because colts are preferred for dressage and endurance while fillies are desired as polo ponies. To date the only effective methodology validated in numerous laboratories is based on measuring the relative DNA content of $\mathrm{X}$ and $\mathrm{Y}$ chromosome bearing spermatozoa (Keeler et al., 1983; Morrell et al., 1988; Johnson, 1995; 1997; Johnson et al., 1999). This technology involves staining spermatozoa with the probe Hoechst 33342 (Morrell et al., 1988; Garner, 2009), a non-intercalating permanent nucleic acid stain that binds to the minor groove of the 
DNA helix (Teng et al., 1988). Stallion sperm are stained, in most studies, with concentrations of Hoechst 33342 ranging from 15 to $90 \mu \mathrm{M}$ (Buss et al., 2005; Mari et al., 2010; Gibb et al., 2011) although occasionally larger dosages have been used (Buchanan et al., 2000) for up to 90 minutes at 34 or $35^{\circ} \mathrm{C}$. After staining, a flow cytometer cell sorter is used to detect the difference in the relative amount of DNA and subsequently to separate the spermatozoa. Sex sorting is commercially available in the cattle industry (Frijters et al., 2009), however developments in sex sorting technology in the horse industry are much less developed (Gibb et al., 2011), due amongst many other reasons to a lesser fertility of the sorted sperm and a reduced efficiency of the sex sorting procedure in horses, owing at least partially to the opaque skim milk based media used during Hoechst 33342 staining. To improve the efficacy of this technology in horses, all the stresses that the spermatozoa suffer during the procedure should be critically evaluated (Morris, 2005; Rath et al., 2009). These stresses include the amount of dilution, high pressure in the flow cytometer, laser exposition and the possible detrimental effect of the staining with Hoechst 33342. The latter has not been critically evaluated with horses. There are, however, some controversial reports in swine and in cattle studies. In the first case a potential protective effect to boar sperm during sorting has been proposed (Guthrie et al., 2002), while in bulls Hoechst 33342 at a concentration of 90 $\mu \mathrm{M}$ reduced oxygen consumption of thawed sperm (Downing et al., 1991), however, $900 \mu \mathrm{M}$ Hoechst 33342 completely abolished human sperm motility, while little effect was noted at 90 $\mu \mathrm{M}$ (Watkins et al., 1996), however, in boars, motility significantly decreased at $60 \mu \mathrm{M}$, and was completely abolished at $90 \mu \mathrm{M}$ (Vazquez et al., 2002). The improvement of this technology in horses requires an in-depth knowledge of all the potential factors affecting the process, especially the identification of the causes of any damage that the stallion spermatozoa may suffer during the process to enable the latter to be minimized. Because 
there are few data on the possible detrimental effect of Hoechst 33342 for stallion sperm, the present study was conducted to investigate the effect of a wide range of concentrations of Hoechst 33342 on stallion spermatozoa incubated in two different extenders. One of the extenders was modified to reduce opacity of the media without reduction the capacity to preserve spermatozoa during incubation.

\section{Materials and methods}

\subsection{Semen collection}

Semen (four ejaculates per stallion) was obtained from two Pure Spanish Stallions (PRE), one cross-breed, one Spanish Arabian horse and one Spanish Sports Horse individually housed at the Veterinary Teaching Hospital of the University of Extremadura, Cáceres, Spain. The stallions were maintained according to institutional and European regulations, and ejaculates were collected on a regular basis (two collections/week) during the 2010 breeding season, using a Missouri model artificial vagina with an inline filter to separate the gel fraction, lubricated and pre-warmed at 45 to $50{ }^{\circ} \mathrm{C}$. The collected ejaculate was immediately transported to the laboratory for evaluation and processing.

\subsection{Semen processing}

The filtered ejaculate was then divided in two, each part being extended 1:1 (v/v) in one of two extenders: INRA96 (IMV, L'Aigle, France)-Tyrodes (65\% of INRA96 and 35\% of modified Tyrodes solution, yielding $71.86 \mathrm{mM} \mathrm{NaCl}, 1.0 \mathrm{mM}$ NaPyruvate, $24.99 \mathrm{mM}$ $\mathrm{NaHCO}_{3}, 3.1 \mathrm{~mL}$ Lactic Acid (60\%), $1.99 \mathrm{mM} \mathrm{CaCl}_{2}, 25.08 \mathrm{mM} \mathrm{KCl}, 0.84 \mathrm{mM}$ $\mathrm{MgCl}_{2} * 6 \mathrm{H}_{2} \mathrm{O}, 0.406 \mathrm{mM} \mathrm{NaH} 2 \mathrm{PO}_{4}$ and $9.98 \mathrm{mM}$ HEPES) and Kenney Modified Tyrodes (65\% of Kenney extender, consisting of $49 \mathrm{~g}$ of Skim Milk Powder in one liter of Nanopure 
water and $133 \mathrm{mM}$ of glucose, and $35 \%$ of modified Tyrodes solution, with $163 \mu \mathrm{M}$ of Penicilin $\mathrm{G}$ and $68.4 \mu \mathrm{M}$ of Streptomycin Sulfate added). Samples were centrifuged at $400 \mathrm{~g}$ for 10 minutes at room temperature $\left(22^{\circ} \mathrm{C}\right)$ and the resulting sperm pellet was re-extended each in the same medium to a final concentration of $111 \times 10^{6}$ spermatozoa $/ \mathrm{mL}$, measured on a Bürker chamber. All products were bought from Sigma-Aldrich Corporation, St. Louis, MO, USA, and $\mathrm{pH}$ adjusted to 7.2.

The two samples obtained were each split into 10 aliquots, placing $1.8 \mathrm{~mL}$ in each tube. To achieve a concentration of $100 \times 10^{6}$ spermatozoa/mL, $200 \mu \mathrm{L}$ of the corresponding extender with $0,1,2,5,7,10,12,15,17$ and $20 \mu \mathrm{L}$ of a stock solution of $8,89 \mathrm{mM}$ Hoechst 33342 (Sigma-Aldrich Corporation, St. Louis, MO, USA), prepared in Nanopure water, were added to the aliquots. This permitted obtaining final concentration values ranging from 0 to $90 \mu \mathrm{M}$.

Ejaculates were then incubated up to 90 minutes in presence of $0,4.5,9,22.5,31.5$, 45, 54, 67.5, 76.5 and $90 \mu \mathrm{M}$ Hoescht 33342, in two media, KMT or INRA-Tyrodes. After 40 and 90 minutes of incubation, motility (CASA) and membrane integrity (flow cytometry after YoPro-1/Eth staining) were evaluated.

\subsection{Sperm motility analysis}

Motility was measured using a computer-assisted sperm analysis system (CASA System, ISAS® Proiser, Valencia, Spain), based on the examination of 25 consecutive, digitalized images obtained from a single field using a 10x negative phase contrast objective in a light microscope (Olympus CX41, Tokyo, Japan), as previously described for stallion sperm (Macias Garcia et al., 2009; Ortega-Ferrusola et al., 2009). Images were taken with a time lapse of $1 \mathrm{~s}$, being image capture speed of one every $40 \mathrm{~ms}$. The number of objects 
121 incorrectly identified as spermatozoa was minimized on the monitor by using the playback

122 function. Regarding the setting parameters of the program, a spermatozoon was considered

123 immotile when presenting a VCL $<10 \mu \mathrm{m} / \mathrm{s}$, and motile if it was $>15 \mu \mathrm{m} / \mathrm{s}$. Cells which

124 deviated $<45 \%$ from a straight line were designed as progressive motile. Cells with a VCL >

$12545 \mu \mathrm{m} / \mathrm{s}$ were considered as rapid sperm. Sperm motion absolute and re-calculated kinematic

126 parameters measured by CASA included the following:

127

128

129

\begin{tabular}{|c|c|c|}
\hline Curvilinear Velocity (VCL) & $\mu \mathrm{m} / \mathrm{s}$ & $\begin{array}{l}\text { Measures the sequential progression along the } \\
\text { true trajectory }\end{array}$ \\
\hline Linear Velocity (VSL) & $\mu \mathrm{m} / \mathrm{s}$ & $\begin{array}{l}\text { Measures the straight trajectory of the } \\
\text { spermatozoa per unit time }\end{array}$ \\
\hline Mean Velocity (VAP) & $\mu \mathrm{m} / \mathrm{s}$ & $\begin{array}{l}\text { Measures the mean trajectory } \\
\text { spermatozoa per unit time }\end{array}$ \\
\hline Linearity Coefficient (LIN) & $\%$ & VSL/VCL x 100 \\
\hline $\begin{array}{l}\text { Straightness Coefficient } \\
\text { (STR) }\end{array}$ & $\%$ & VSL/VAP x 100 \\
\hline Wobble Coefficient (WOB) & $\%$ & VAP/VCL x 100 \\
\hline $\begin{array}{l}\text { Average lateral head } \\
\text { displacement }(\mathrm{ALH})\end{array}$ & $\mu \mathrm{m}$ & $\begin{array}{l}\text { Measures the mean head displacement along the } \\
\text { curvilinear trajectory }\end{array}$ \\
\hline $\mathrm{BCF}$ & $\mathrm{Hz}$ & $\begin{array}{l}\text { Number of times the sperm head crosses the } \\
\text { mean path/second }\end{array}$ \\
\hline
\end{tabular}


133 al. (Pena et al., 2005) with modifications for adaptation to the equine species (Ortega-

134 Ferrusola et al., 2008; Ortega Ferrusola et al., 2009b; Ortega Ferrusola et al., 2009c). In brief, 135 one $\mathrm{mL}$ of sperm suspension ( $5 \times 10^{6}$ spermatozoa/mL) was loaded with $3 \mu \mathrm{L}$ of Yo-Pro-1 $136(25 \mu \mathrm{M})$ and one $\mu \mathrm{L}$ of Ethidium Homodimer-1 (1.167 mM) (Molecular Probes Europe), 137 which -after thorough mixing- was incubated at $37^{\circ} \mathrm{C}$ in the dark for $16 \mathrm{~min}$. This staining 138 distinguishes four sperm subpopulations. The first is the subpopulation of unstained 139 spermatozoa. These spermatozoa are considered alive and without any membrane alteration. 140 Another sperm subpopulation consists of Yo-Pro-1 positive cells emitting green fluorescence.

141 In the early stages of apoptosis there is a modification of membrane permeability that 142 selectively allows entry of some non-permeable DNA-binding molecules. This subpopulation 143 groups spermatozoa which may show a shift to another physiological state or early damage, 144 since membranes become slightly permeable during the first steps of injury, enabling Yo-Pro-

1451 but not ethidium homodimer to penetrate the plasma membrane (Idziorek et al., 1995).

146 None of these probes enters intact cells. Finally, two subpopulations of necrotic spermatozoa 147 were easily detected: early necrotic, spermatozoa stained both with Yo-Pro-1 and ethidium 148 homodimer (emitting both green and red fluorescence), and late necrotic spermatozoa, cells 149 stained only with ethidium homodimer (emitting red fluorescence).

\subsection{Flow cytometry analysis}

Flow cytometric analyses were carried out with a Coulter EPICS XL (Coulter

153 Corporation Inc., Miami, FL, USA) flow cytometer equipped with standard optics, an argon154 ion laser (Cyonics, Coherent, Santa Clara, CA, USA) performing $15 \mathrm{~mW}$ at $488 \mathrm{~nm}$ and 
155 EXPO 2000 software. Subpopulations were divided by quadrants, and the frequency of each

156 subpopulation was quantified. Non-sperm events (debris) were identified and eliminated from

157 the analysis as described in (Petrunkina et al., 2010). Forward and sideways light scatter were

158 recorded for a total of 10,000 events per sample. Samples were measured at flow rate of 200

159 to 300 cells/sec. Green fluorescence was detected in FL1 (525 nm band pass filter) red

160 fluorescence was detected in FL3 (620 nm band pass filter), and orange fluorescence in FL2

161 (570 nm band pass filter).

162 2.6. Statistical analysis

163 Data were first examined using the Kolmogorov-Smirnov test to determine their

164 distribution, a multivariate analysis of variance was performed (ANOVA) and when

165 significant differences were found, the non-parametric Mann-Whitney U-test was used to 166 compare pairs of values directly if data did not adjust to a normal distribution. All analyses

167 were performed using SPSS version 17.0 for Windows (SPSS Inc., Chicago, IL). The 168 Spearman non-parametric test was used to study the correlations among apoptosis and 169 autophagy and the results of the sperm analysis. Significance was set at $P<0.05$

172 3. Results

173 3.1. Effect on sperm motility and kinematics at the beginning of incubation at $35^{\circ} \mathrm{C}$

174 At concentrations equal or above $31.5 \mu \mathrm{M}$ Hoechst 33342 affected some parameters of

175 sperm kinematics, however, there was no effect on the percentages of total motile sperm,

176 progressive motile or the percentage of rapid sperm, these changes related to linearity, 177 straightness and wobble. VCL was reduced by Hoechst 33342 at $45 \mu \mathrm{M}$ and $67.5 \mu \mathrm{M}$

$178 \quad(P<0.01)$ but only in those spermatozoa incubated in KMT extender. However at 76.5 and 90 
$\mu \mathrm{M}$, Hoechst $33342 \mathrm{VCL}$ was reduced in both extenders $(P<0.05)$. VAP was reduced when spermatozoa were incubated in presence of $67.6(P<0.05)$ and $90 \mu \mathrm{M}(P<0.01)$ Hoechst

18133342 buy only in those samples extended in KMT (Figures 1-3).

182

\subsection{Effect on sperm motility and kinematics after 40 minutes of incubation at $35^{\circ} \mathrm{C}$}

The first changes were observed in those spermatozoa incubated at a concentration of

$31.5 \mu \mathrm{M}$. The changes observed were a decrease in ALH and an increase in the linearity in spermatozoa incubated in Tyrodes modified INRA 96.. Incubation in the presence of 45 and $55 \mu \mathrm{M}$ resulted in a decrease in the percentage of progressive, rapid sperm and VAP, but only in samples extended in KMT $(P<0.05)$, VCL was reduced in both extenders $(P<0.05)$ while linearity was increased in samples extended in Tyrodes-Modified INRA $(P<0.05)$. At concentrations of 67.5 and $76.5 \mu \mathrm{M}$, there was also a decrease in the percentage of total motile sperm $(P<0.05)$ but only in samples extended in KMT. At the concentration of $90 \mu \mathrm{M}$ the decrease was observed in both extenders $(P<0.05$; Figures 1-3).

\subsection{Effect on sperm motility and kinematics after 90 minutes of incubation at $35^{\circ} \mathrm{C}$}

Hoechst 33342 staining produced a dose-dependent effect on sperm motility and kinematics. Concentrations above $31.5 \mu \mathrm{M}$ resulted in a significant effect, reducing the percentage of progressive motile sperm, the percentage of rapid progressive sperm and VCL

198 in both extenders. At a concentration of $45 \mu \mathrm{M}$ and $54 \mu \mathrm{M}$, the staining also reduced the 199 percentage of total motile sperm, but only when incubated in KMT media and not in Tyrodes Modified INRA 96. Similarly, the concentration of $45 \mu \mathrm{M}$ reduced VAP, but only in 201 spermatozoa incubated in KMT media. Concentrations equal or above $67.5 \mu \mathrm{M}$ also resulted 
values were superior in samples incubated in Tyrodes modified INRA 96 both at 40 and 90 minutes of incubation $(P<0.01$; Figures $1-3)$.

\subsection{Effect on early membrane changes and viability after incubation up to 90 minutes}

There was no effect of the Hoechst 33342 in the sperm membranes of spermatozoa at any time considered in spermatozoa incubated in both media (Figure 4).

\section{Discussion}

In the present study, the effect of Hoechst 33342 on stallion spermatozoa incubated up

212 to 90 minutes at $35^{\circ} \mathrm{C}$ was evaluated. This is the first report in stallions evaluating the effect 213 of the dye on sperm motility and kinematics using CASA analysis and sperm membranes evaluated using flow cytometry. Hoechst 33442 exerted a detrimental effect on sperm motility and kinematics that was time- and dose-dependent, but had no effect on the percentage of intact sperm or those showing early or late membrane damage. Interestingly the detrimental 217 effects were reduced in Tyrodes modified INRA 96 extender. Even at the beginning of the 218 incubation period, the dye was able to modify sperm kinematics at concentrations above 31.5 $219 \mu \mathrm{M}$, however, the most striking effects were at concentrations above $67.5 \mu \mathrm{M}$ when circular 220 velocity was affected; after 40 minutes of incubation also an effect on the percentage of rapid 221 sperm was observed at concentrations above $45 \mu \mathrm{M}$, but only in KMT extender. This parameter was only significantly affected in samples extended in Tyrodes modified INRA 96 if Hoechst was present at $90 \mu \mathrm{M}$.

After 90 minutes of incubation, differences in the sperm movement characteristics disappeared, but there was a clear effect of the probe on the percentages of motile, rapid sperm and velocities at concentrations above $31.5 \mu \mathrm{M}$. It is difficult to establish comparisons 
because the amount of information available is limited. However, Clulow et al. (2009) reported a decrease in total motility and an increase in the number of dead spermatozoa after incubation for 90 minutes in the presence of Hoechst 33342 at concentrations ranging from 22.5 to $67.5 \mu \mathrm{M}$, but the exact concentration of the dye for every individual stallion was not 231 given. Kenney’s modified Tyrodes media (KMT; Padilla and Foote, 1991) has been the main 232 media used for incubation and staining stallion sperm to date (Buchanan et al., 2000; Buss et 233 al., 2005; Mari et al., 2010), although recently it has been demonstrated that clear diluents 234 increases the sex sorting efficiency of stallion sperm (Gibb et al., 2011). However in the latter 235 study the effect of the staining on stallion sperm was not included in the experimental 236 protocol. In the present study, the detrimental effect of Hoechst 33342 varied with the 237 extender and thus can be minimized using defined extenders. Minimizing sperm damage 238 along all the steps of the sorting procedure will improve the efficiency of this technology and 239 will facilitate a greater use of sexed semen (Rath et al., 2009). In this regard, Tyrodes 240 modified INRA 96 appeared superior to KMT, being able to keep the percentage of total 241 motile, rapid sperm and velocities more effectively than KMT. These sperm parameters have 242 been recently related to stallion fertility (Love, 2011). The fact that effects on sperm motility 243 and kinematics were seen using Hoechst 33342 concentrations on the range used to stain 244 stallion spermatozoa is noteworthy. Studies in pigs demonstrated that Hoechst 33342 was not 245 detrimental in the range used to stain pig sperm (Vazquez et al., 2002). In bull sperm, 246 apparently the staining does not affect the characteristics of sperm movement as determined 247 using CASA analysis (Penfold et al., 1998). Differences among species are difficult to 248 interpret although factors such as oxygen consumption may be involved (Downing et al., 249 1991). In relation to this, the greater impact on sperm motility in stallions compared with pigs 250 may be related to the different management of energy resources in boar and stallion sperm. 
251 While boar sperm obtains energy for motility mainly from anaerobic pathways (Marin et al., 252 2003), stallion sperm appear to be more dependent on oxidative phosphorylation (Pena et al., 253 2009; Ortega Ferrusola et al., 2010). Furthermore, differences in lipid composition of the 254 sperm membranes may be involved in differing susceptibility to Hoechst 33342 , because the 255 major fatty acid present varies amongst boars (Cerolini et al., 2000), bulls (Schiller et al., 256 2003) and stallions (Macias Garcia et al., 2011).

The most striking finding in the present study, is the extent of the deleterious impact of Hoechst 33342 varies depending on the media used to extend the sperm. As a first practical application, one of the damages of the sex sorting procedure can be diminished simply by 260 changing the media of incubation with the probe. In this regard, Tyrodes modified INRA-96 261 was able to maintain greater sperm velocities and percentages of total and progressive motile sperm at concentrations and times when KMT was not able to sustain motility. Greater sperm motilities are related to greater fertility in stallions (Love, 2011), in addition to human studies indicating that the maintenance of greater sperm velocities are essential for fertilization to occur (Olds-Clarke, 1996; De Geyter et al., 1998). Furthermore, a recent study in red deer 266 clearly relates sperm velocity and fertility (Malo et al., 2005). Thus a steady increasing body of scientific evidence stresses the importance of sperm velocity as an attribute of fertile sperm.

In the present study the effect of Hoechst 33342 of sperm membrane intactness and 270 early changes were also evaluated. A combination of probes was used that allows the 271 identification of early damage on the sperm membrane (Ortega Ferrusola et al., 2009a; Ortega 272 Ferrusola et al., 2009c) in an attempt to disclose subtle changes. Hoechst had no effect in sperm membrane intactness or in early damage. 
In summary, Hoechst 33342 exerts a negative effect on sperm motility and kinematics,

that is dose and time dependent without affecting the intactness of sperm membranes.

Interestingly these detrimental effects can be minimized by incubating the spermatozoa in a

modified INRA 96 media, in comparison to the traditionally used KMT extender, thus

opening an approach to minimize the damage that stallion spermatozoa experience during the

sorting process.

\section{Acknowledgements}

The investigations of the authors received financial support from Ministerio de

Ciencia e Innovación- FEDER Madrid, Spain Grants AGL 2010- 20758 (GAN), and Junta de

Extremadura FEDER GR 10010 and PCE 1002. The generous collaboration of the Service of

Equine Breeding of the Spanish Army is acknowledged

\section{References}

Buchanan, B.R., Seidel, G.E., Jr., McCue, P.M., Schenk, J.L., Herickhoff, L.A., Squires, E.L., 2000. Insemination of mares with low numbers of either unsexed or sexed spermatozoa. Theriogenology 53, 1333-1344.

Buss, H., Clulow, J., Sieme, H., Maxwell, W.M., Morris, L.H., Sieg, B., Struckmann, C., Rath, D., 2005. Improvement of the freezability of sex-sorted stallion spermatozoa. Anim. Reprod. Sci. 89, 315-318.

Cerolini, S., Maldjian, A., Surai, P., Noble, R., 2000. Viability, susceptibility to peroxidation and fatty acid composition of boar semen during liquid storage. Anim. Reprod. Sci. $58,99-111$.

Clulow, J.R., Evans, G., Morris, L.H., Maxwell, W.M., 2009. Factors influencing the "sortability" of stallion spermatozoa into X- and Y-chromosome bearing populations. Anim. Reprod. Sci. 113, 220-228.

De Geyter, C., De Geyter, M., Koppers, B., Nieschlag, E., 1998. Diagnostic accuracy of computer-assisted sperm motion analysis. Hum. Reprod. 13, 2512-2520.

Downing, T.W., Garner, D.L., Ericsson, S.A., Redelman, D., 1991. Metabolic toxicity of fluorescent stains on thawed cryopreserved bovine sperm cells. J. Histochem. Cytochem. 39, 485-489. 
Frijters, A.C., Mullaart, E., Roelofs, R.M., van Hoorne, R.P., Moreno, J.F., Moreno, O., Merton, J.S., 2009. What affects fertility of sexed bull semen more, low sperm dosage or the sorting process? Theriogenology 71, 64-67.

Garner, D.L., 2009. Hoechst 33342: the dye that enabled differentiation of living X-and Ychromosome bearing mammalian sperm. Theriogenology 71, 11-21.

Gibb, Z., Morris, L.H., Maxwell, W.M., Grupen, C.G., 2011. Use of a defined diluent increases the sex-sorting efficiency of stallion sperm. Theriogenology 75, 610-619...

Guthrie, H.D., Johnson, L.A., Garrett, W.M., Welch, G.R., Dobrinsky, J.R., 2002. Flow cytometric sperm sorting: effects of varying laser power on embryo development in swine. Mol. Reprod. Dev. 61, 87-92.

Idziorek, T., Estaquier, J., De Bels, F., Ameisen, J.C., 1995. YOPRO-1 permits cytofluorometric analysis of programmed cell death (apoptosis) without interfering with cell viability. J. Immun. Meth. 185, 249-258.

Johnson, L.A., 1995. Sex preselection by flow cytometric separation of $\mathrm{X}$ and $\mathrm{Y}$ chromosome-bearing sperm based on DNA difference: a review. Reprod. Fertil. Dev. 7, 893-903.

Johnson, L.A., 1997. Advances in gender preselection in swine. J. Reprod. Fertil. Suppl. 52, 255-266.

Johnson, L.A., Welch, G.R., Rens, W., 1999. The Beltsville sperm sexing technology: highspeed sperm sorting gives improved sperm output for in vitro fertilization and AI. J. Anim. Sci. 77 Suppl 2, 213-220.

Keeler, K.D., Mackenzie, N.M., Dresser, D.W., 1983. Flow microfluorometric analysis of living spermatozoa stained with Hoechst 33342. J. Reprod. Fertil. 68, 205-212.

Love, C.C., 2011. Relationship between sperm motility, morphology and the fertility of stallions. Theriogenology. 76; 547-557

Macias Garcia, B., Gonzalez Fernandez, L., Morrell, J.M., Ortega Ferrusola, C., Tapia, J.A., Rodriguez Martinez, H., Pena, F.J., 2009. Single-layer centrifugation through colloid positively modifies the sperm subpopulation structure of frozen-thawed stallion spermatozoa. Reprod. Domest. Anim. 44, 523-526.

Macias Garcia, B., Gonzalez Fernandez, L., Ortega Ferrusola, C., Morillo Rodriguez, A., Gallardo Bolanos, J.M., Rodriguez Martinez, H., Tapia, J.A., Morcuende, D., Pena, F.J., 2011. Fatty acids and plasmalogens of the phospholipids of the sperm membranes and their relation with the post-thaw quality of stallion spermatozoa. Theriogenology $75,811-818$.

Malo, A.F., Garde, J.J., Soler, A.J., Garcia, A.J., Gomendio, M., Roldan, E.R., 2005. Male fertility in natural populations of red deer is determined by sperm velocity and the proportion of normal spermatozoa. Biol, Reprod, 72, 822-829.

Mari, G., Rizzato, G., Merlo, B., Iacono, E., Bucci, D., Seren, E., Tamanini, C., Galeati, G., Spinaci, M., 2010. Quality and fertilizing ability in vivo of sex-sorted stallion spermatozoa. Reprod, Domest, Anim, 45, 331-335.

Marin, S., Chiang, K., Bassilian, S., Lee, W.N., Boros, L.G., Fernandez-Novell, J.M., Centelles, J.J., Medrano, A., Rodriguez-Gil, J.E., Cascante, M., 2003. Metabolic strategy of boar spermatozoa revealed by a metabolomic characterization. FEBS Lett. 554, 342-346.

Morrell, J.M., Keeler, K.D., Noakes, D.E., Mackenzie, N.M., Dresser, D.W., 1988. Sexing of sperm by flow cytometry. Vet. Rec. 122, 322-324.

Morris, L.H., 2005. Challenges facing sex preselection of stallion spermatozoa. Anim. Reprod. Sci. 89, 147-157. 
Olds-Clarke, P., 1996. How does poor motility alter sperm fertilizing ability? J. Androl. 17, 183-186.

Ortega Ferrusola, C., Gonzalez Fernandez, L., Macias Garcia, B., Salazar-Sandoval, C., Morillo Rodriguez, A., Rodriguez Martinez, H., Tapia, J.A., Pena, F.J., 2009a. Effect of cryopreservation on nitric oxide production by stallion spermatozoa. Biol. Reprod. 81, 1106-1111.

Ortega Ferrusola, C., Gonzalez Fernandez, L., Macias Garcia, B., Salazar-Sandoval, C., Morillo Rodriguez, A., Rodriguez Martinez, H., Tapia, J.A., Pena, F.J., 2009b. Effect of cryopreservation on nitric oxide production by stallion spermatozoa. Biol. Reprod. 81, 1106-1111.

Ortega Ferrusola, C., Gonzalez Fernandez, L., Morrell, J.M., Salazar Sandoval, C., Macias Garcia, B., Rodriguez-Martinez, H., Tapia, J.A., Pena, F.J., 2009c. Lipid peroxidation, assessed with BODIPY-C11, increases after cryopreservation of stallion spermatozoa, is stallion-dependent and is related to apoptotic-like changes. Reproduction 138, 5563.

Ortega Ferrusola, C., Gonzalez Fernandez, L., Salazar Sandoval, C., Macias Garcia, B., Rodriguez Martinez, H., Tapia, J.A., Pena, F.J., 2010. Inhibition of the mitochondrial permeability transition pore reduces "apoptosis like" changes during cryopreservation of stallion spermatozoa. Theriogenology 74, 458-465.

Ortega-Ferrusola, C., Macias Garcia, B., Suarez Rama, V., Gallardo-Bolanos, J.M., GonzalezFernandez, L., Tapia, J.A., Rodriguez-Martinez, H., Pena, F.J., 2009. Identification of sperm subpopulations in stallion ejaculates: changes after cryopreservation and comparison with traditional statistics. Reprod. Domest. Anim. 44, 419-423.

Ortega-Ferrusola, C., Sotillo-Galan, Y., Varela-Fernandez, E., Gallardo-Bolanos, J.M., Muriel, A., Gonzalez-Fernandez, L., Tapia, J.A., Pena, F.J., 2008. Detection of "apoptosis-like" changes during the cryopreservation process in equine sperm. J. Androl. 29, 213-221.

Padilla, A.W., Foote, R.H., 1991. Extender and centrifugation effects on the motility patterns of slow-cooled stallion spermatozoa. J. Anim. Sci. 69, 3308-3313.

Pena, F.J., Rodriguez Martinez, H., Tapia, J.A., Ortega Ferrusola, C., Gonzalez Fernandez, L., Macias Garcia, B., 2009. Mitochondria in mammalian sperm physiology and pathology: a review. Reprod. Domest. Anim. 44, 345-349.

Pena, F.J., Saravia, F., Johannisson, A., Walgren, M., Rodriguez-Martinez, H., 2005. A new and simple method to evaluate early membrane changes in frozen-thawed boar spermatozoa. Int. J. Androl. 28, 107-114.

Penfold, L.M., Holt, C., Holt, W.V., Welch, G.R., Cran, D.G., Johnson, L.A., 1998. Comparative motility of $\mathrm{X}$ and $\mathrm{Y}$ chromosome-bearing bovine sperm separated on the basis of DNA content by flow sorting. Mol. Reprod. Dev. 50, 323-327.

Petrunkina, A.M., Waberski, D., Bollwein, H., Sieme, H., 2010. Identifying non-sperm particles during flow cytometric physiological assessment: a simple approach. Theriogenology 73, 995-1000.

Rath, D., Moench-Tegeder, G., Taylor, U., Johnson, L.A., 2009. Improved quality of sexsorted sperm: a prerequisite for wider commercial application. Theriogenology 71, 2229.

Schiller, J., Muller, K., Suss, R., Arnhold, J., Gey, C., Herrmann, A., Lessig, J., Arnold, K., Muller, P., 2003. Analysis of the lipid composition of bull spermatozoa by MALDITOF mass spectrometry--a cautionary note. Chem. Phys. Lipids 126, 85-94. 
Teng, M.K., Usman, N., Frederick, C.A., Wang, A.H., 1988. The molecular structure of the complex of Hoechst 33258 and the DNA dodecamer d(CGCGAATTCGCG). Nucleic Acids Res. 16, 2671-2690.

Vazquez, J.M., Martinez, E.A., Parrilla, I., Gil, M.A., Lucas, X., Roca, J., 2002. Motility characteristics and fertilizing capacity of boar spermatozoa stained with Hoechst 33342. Reprod. Domest. Anim. 37, 369-374.

Watkins, A.M., Chan, P.J., Kalugdan, T.H., Patton, W.C., Jacobson, J.D., King, A., 1996. Analysis of the flow cytometer stain Hoechst 33342 on human spermatozoa. Mol. Hum. Reprod. 2, 709-712.

\section{FIGURE LEGENDS}

Fig. 1. Progressive motility (means \pm SE) of stallion sperm incubated in presence of Hoechst 33342 up to 90 minutes in two different media KMT (Kenney's modified Tyrodes) and INRA-T (INRA modified Tyrode's). Comparisons are made against the controls at the beginning of the incubation period, after 40 minutes of incubation, and after 90 minutes of incubation. $* P<0.05 ; * * P<0.01$

Fig. 2. Percentage of rapid sperm (VCL $>45 \mu \mathrm{m} / \mathrm{s}$ ) of stallion sperm incubated in presence of Hoechst 33342 up to 90 minutes in two different media KMT (Kenney's modified Tyrodes) and INRA-T (INRA modified Tyrode's). Comparisons are made against the controls at the beginning of the incubation period, after 40 minutes of incubation, and after 90 minutes of incubation. $* P<0.05 ; * * P<0.01$

Fig. 3. Sperm velocities: VCL $\mu \mathrm{m} / \mathrm{s}$ (circular velocity), VSL $\mu \mathrm{m} / \mathrm{s}$ (straight line velocity) and $\mathrm{VAP} \mu \mathrm{m} / \mathrm{s}$ (average velocity) of stallion sperm incubated in presence of Hoechst 33342 up to 
43090 minutes in two different media KMT (Kenney's modified Tyrodes) and INRA-T (INRA

431 modified Tyrode's). Comparisons are made against the controls at the beginning of the

432 incubation period, after 40 minutes of incubation, and after 90 minutes of incubation.

$433 * P<0.05 ; * * P<0.01$

434

435 Fig. 4. Percentage of spermatozoa with intact membranes after YoPro-1/Eth staining as 436 described in material and methods of stallion sperm incubated in presence of Hoechst 33342 437 up to 90 minutes in two different media KMT (Kenney's modified Tyrodes) and INRA-T 438 (INRA modified Tyrode's). Comparisons are made against the controls at the beginning of the 439 incubation period, after 40 minutes of incubation, and after 90 minutes of incubation.

440

441

442 


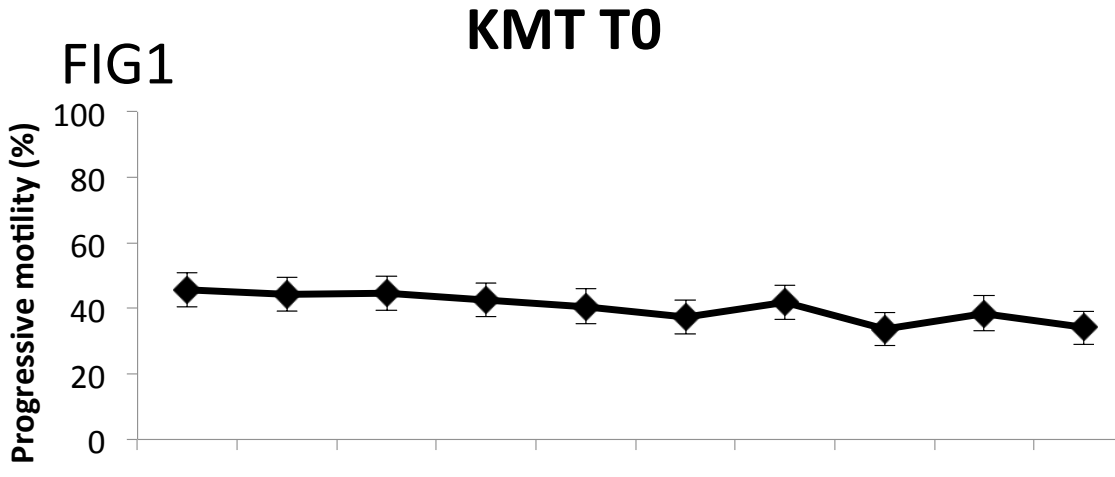

KMT T40
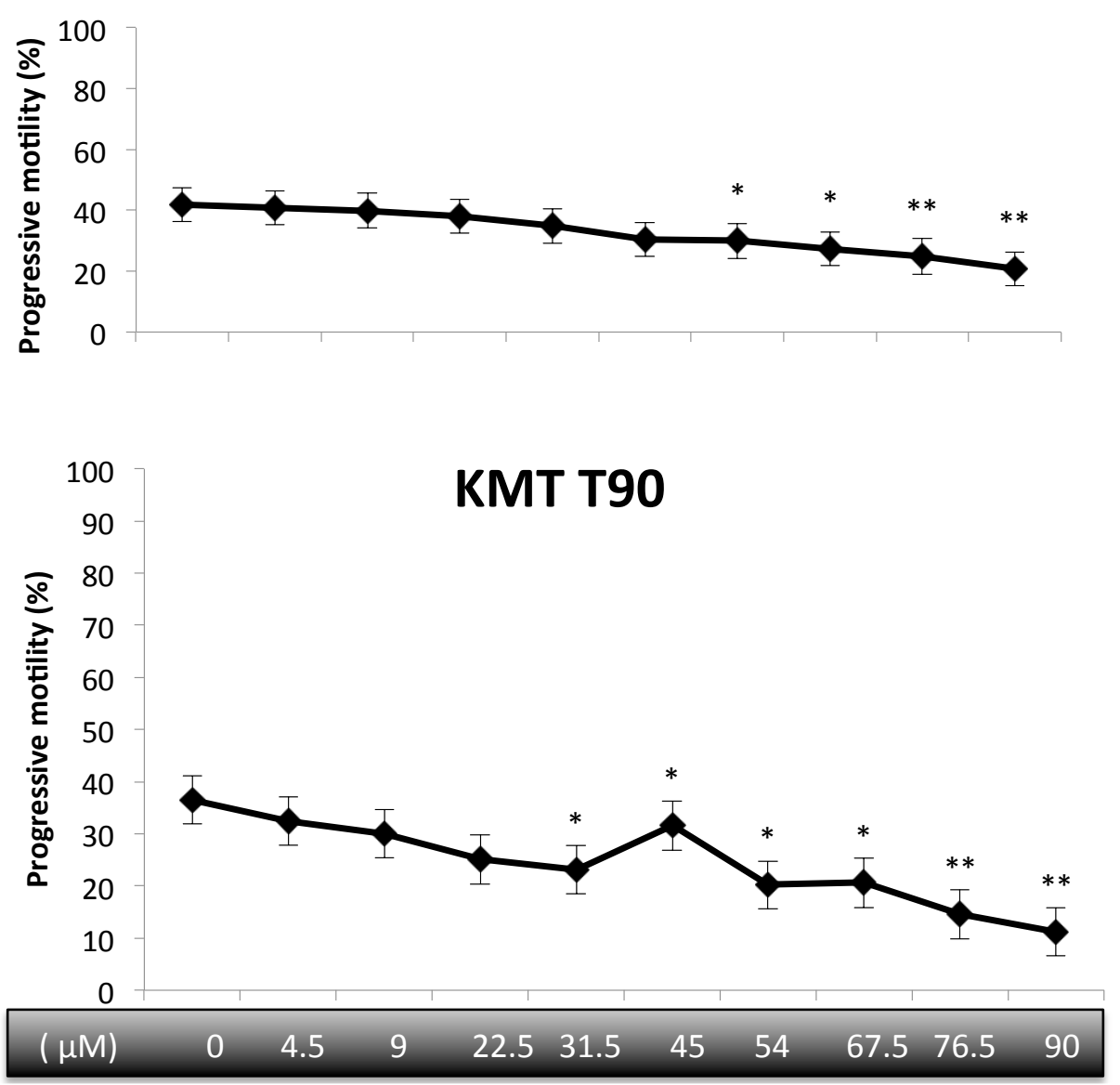

INRA-T TO

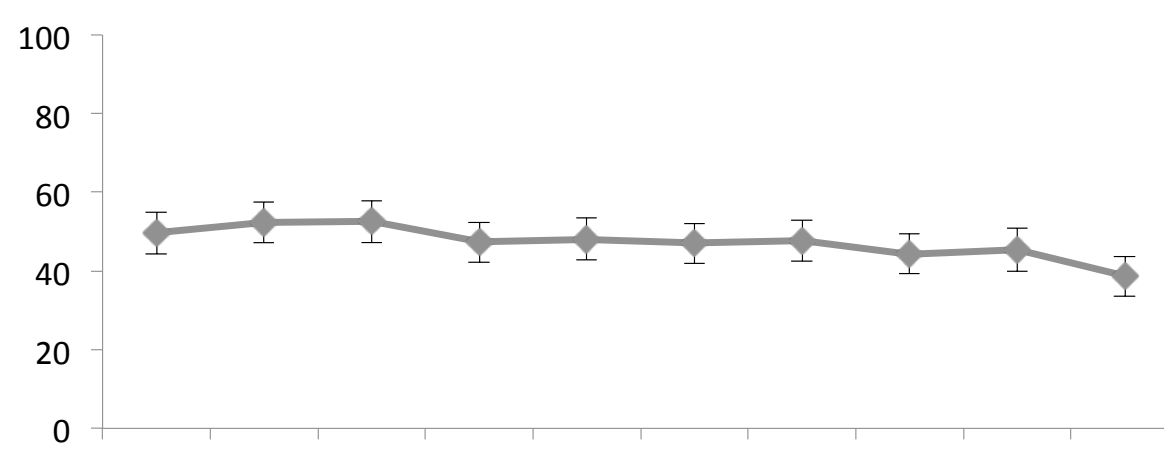

INRA-T T40
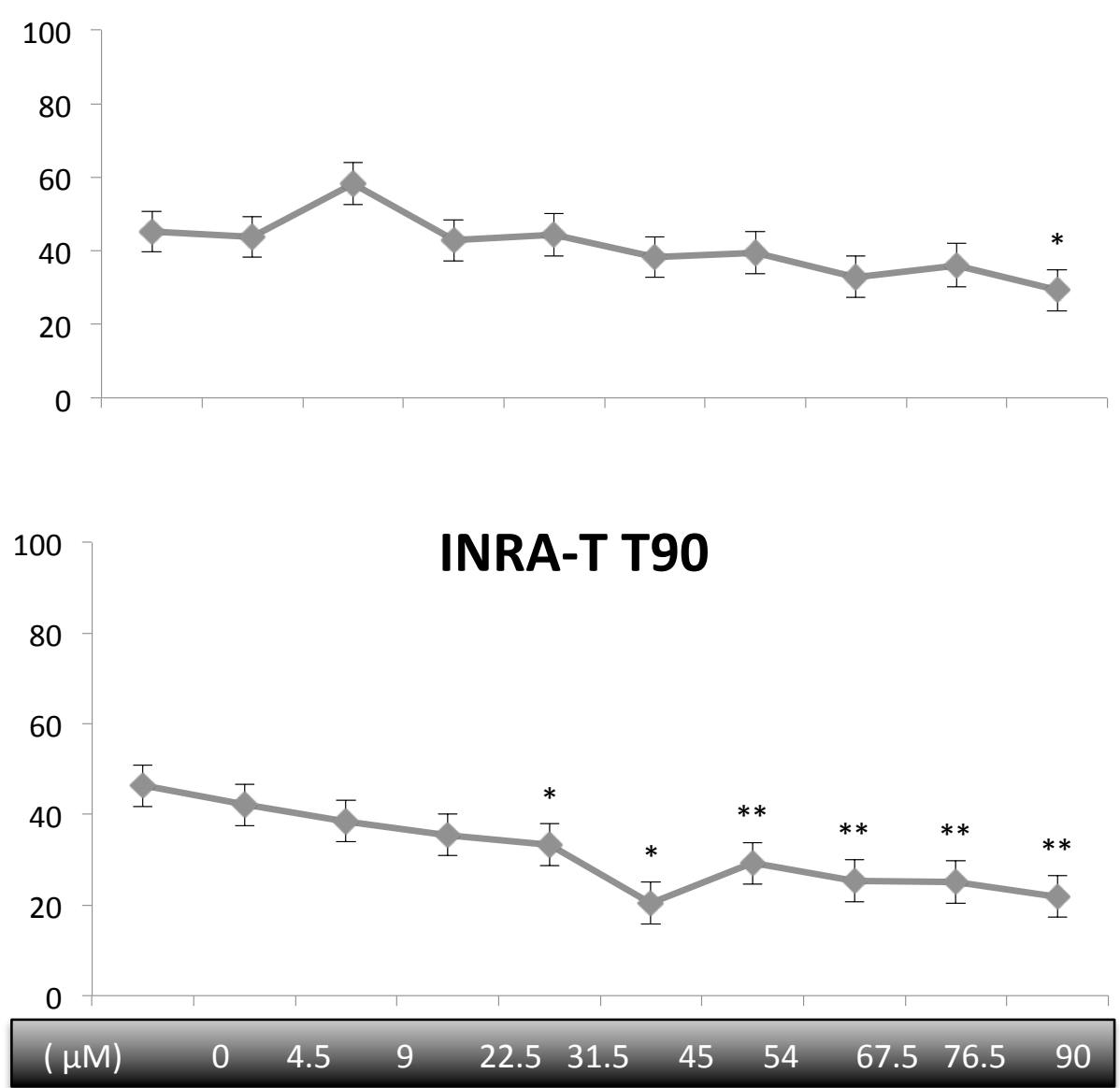

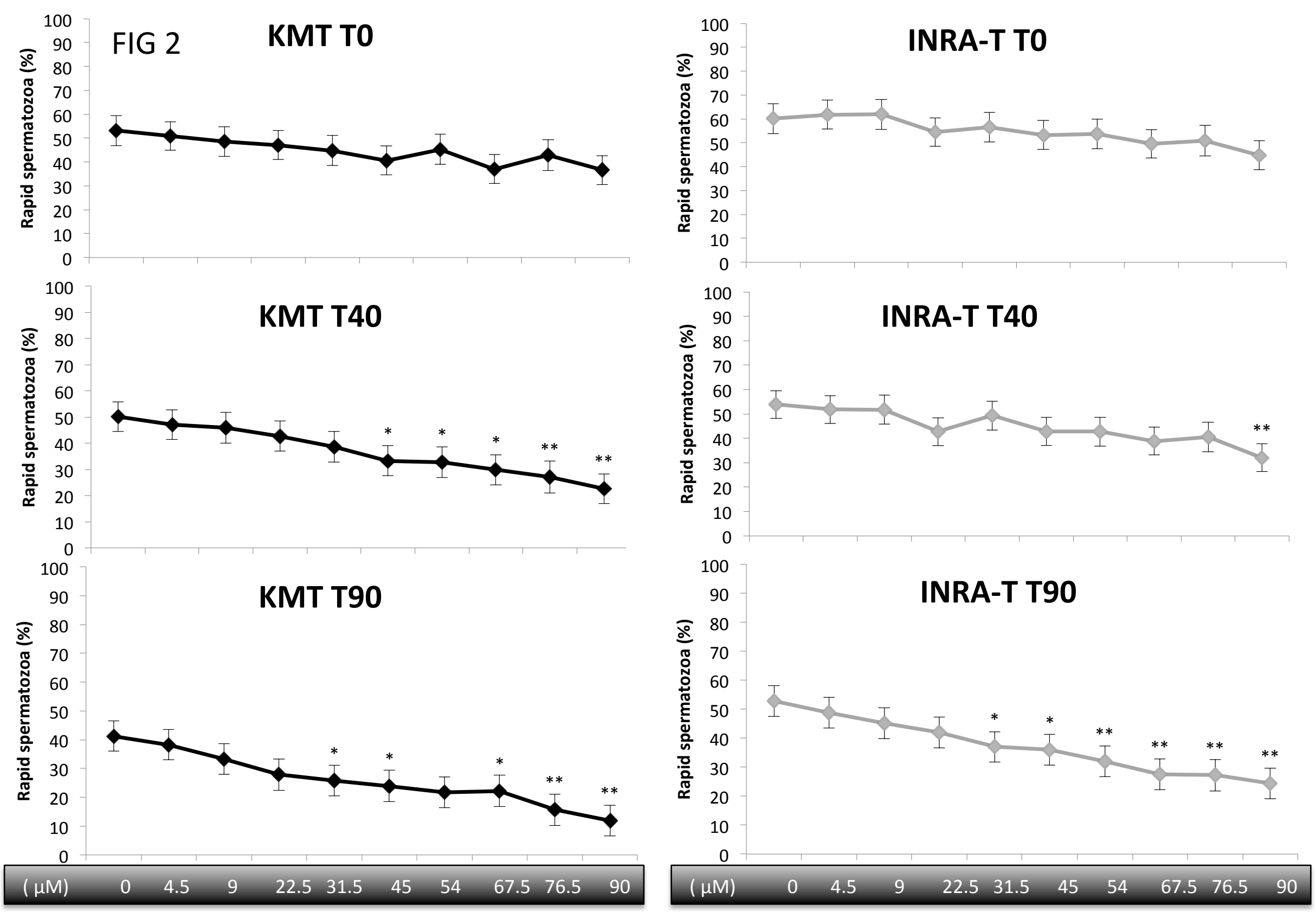

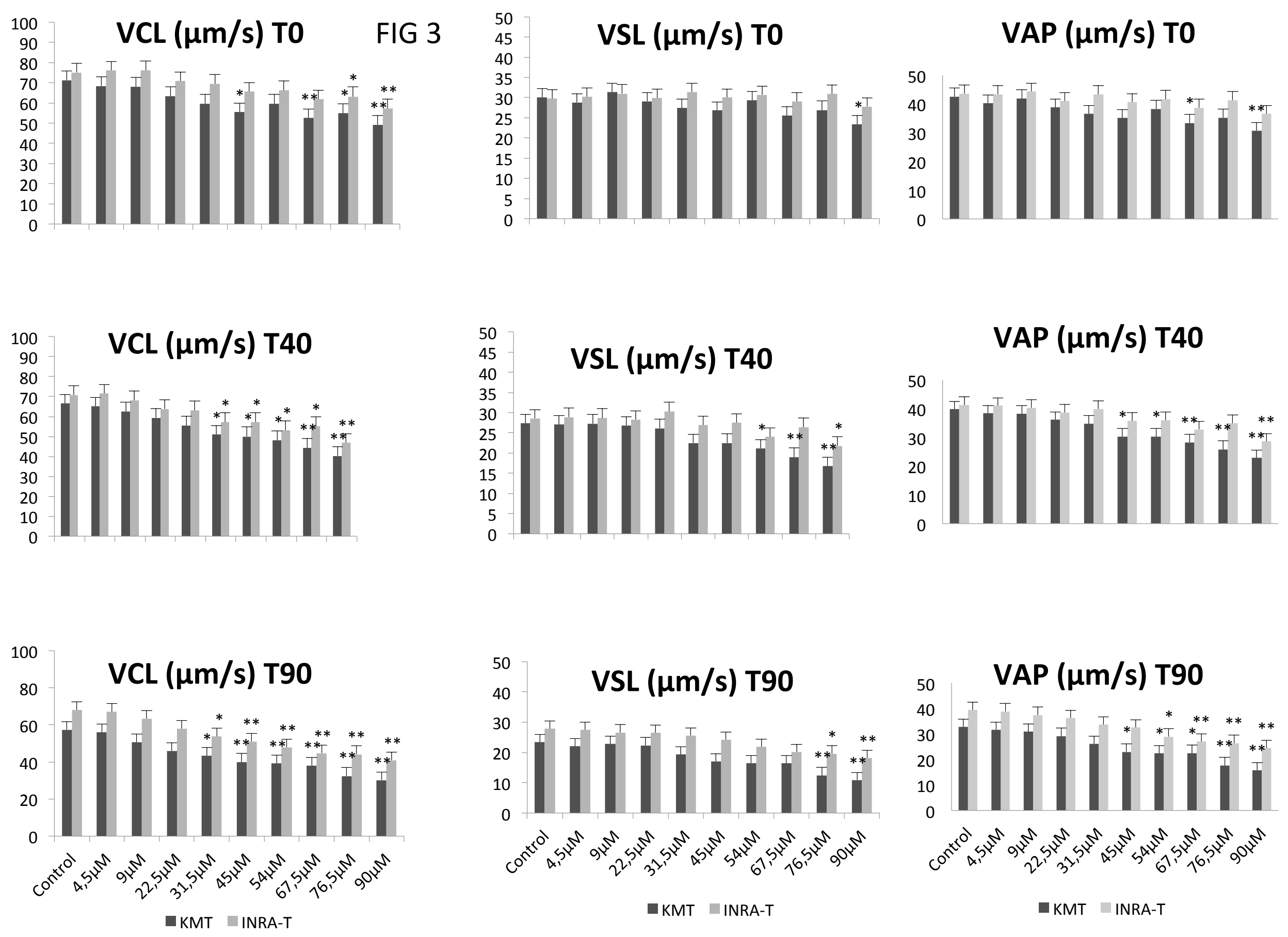
FIG 4

Intact TO
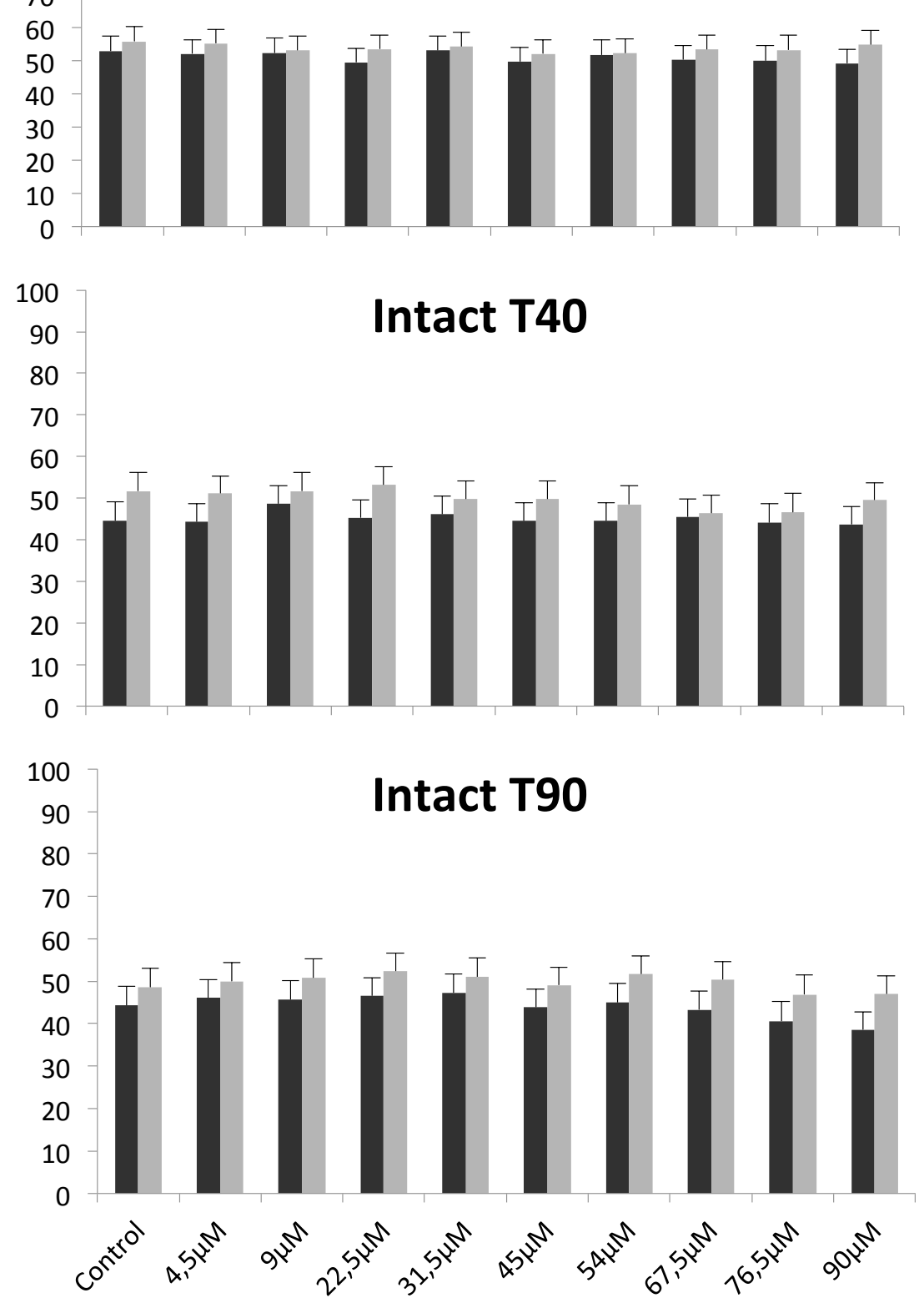